\title{
HIPERENUNCIADOR: O OUTRO DO SUPRADESTINATÁRIO? ${ }^{1}$
}

\author{
Maria Marta Furlanetto ${ }^{2}$
}

Resumo: O objetivo neste ensaio é verificar se a noção de "biperenunciador", proposta e desenvolvida por Maingueneau (2005a, 2008) em seus últimos trabalhos de Análise do Discurso, teria correlação com a noção genérica de "terceiro" (investigada em suas variantes) na teoria do Círculo de Bakbtin. Tem-se como proposta examinar uma aproximação ou inspiração para rever questões associadas aos gêneros instituídos, incluindo a autoria. Busca-se estabelecer seu modo de funcionamento e as implicacões relativas ao processo de autoria. Observa-se, em conclusão, que o entendimento de supradestinatário (como "terceiro") vai desde uma instância vinculada ao ego, um duplo do enunciador, até uma instância externa, independente do enunciador (o terceiro com marca coletiva), como um conjunto de normas que é preciso seguir para a aceitação do texto (numa comunidade de discurso), estendendo-se ainda a uma forma de discurso interior, até, eventualmente, coincidir com o hiperenunciador.

Palavras-chave: Discurso. Hiperenunciador. Supradestinatário. Autoria.

\section{INTRODUÇÃO}

Meu objetivo neste texto é verificar a hipótese de que a noção recente de "hiperenunciador", como um foco de interesse na análise do discurso desenvolvida por Maingueneau, teria um correlato (independente) na teoria do Círculo de Bakhtin representado pela noção de "terceiro". Como essa noção se mostra difusa, multifacetada, enunciada em períodos diferentes na caminhada teórica do Círculo, a proposta é, pondo em paralelo as duas noções, verificar a possibilidade de alguma aproximação, correlação ou inspiração para investigar questões associadas aos gêneros instituídos, entre as quais aquela de autoria.

Começo pela exposição de elementos do campo em que o Círculo de Bakhtin faz surgir o termo "terceiro", explicitando seu contexto de ocorrência e sua eventual dispersão de sentido. Em seguida, revisito a

\footnotetext{
${ }^{1}$ Agradeço à doutoranda Conceição Kindermann por ter lido e discutido comigo a primeira versão deste trabalho, dando sugestões que incorporei para melhorá-lo.

2 Dra. em Linguística Aplicada. Professora da Universidade do Sul de Santa Catarina - Pósgraduação em Ciências da Linguagem e Curso de Letras. Email: mmarta@intercorp.com.br.
} 
teoria desenvolvida por Maingueneau (2002, 2004, 2005a, 2005b, 2008), enfocando, de suas incursões mais recentes, a noção de hiperenunciador. Finalmente, exploro em paralelo os dois conceitos, associados a outros que circulam em torno deles, para estabelecer seu modo de funcionamento e algumas implicações relativamente à noção de autoria.

\section{O “TERCEIRO” NA OBRA DE BAKHTIN}

Ao abordar o problema do texto nos estudos linguísticos e nas ciências humanas em geral, Bakhtin (2003, p. 330-331) pontua as relações dialógicas, que pressupõem enunciados integrais existentes como gêneros do discurso, e introduz aí a noção de "ponto de vista do terceiro" no diálogo. Essa "figura" não participa do diálogo, mas o entende (a compreensão é uma noção-chave que atravessa toda a obra).

Alguns parágrafos à frente, Bakhtin diz que o entendedor "se torna inevitavelmente um terceiro no diálogo" (p. 332) - não no sentido aritmético - estabelecendo que essa posição dialógica (de terceiro) é "absolutamente específica". Por quê?

É que o destinatário, a quem é dirigido o enunciado, é o segundo (igualmente, não no sentido aritmético). O autor do enunciado "propõe, com maior ou menor consciência, um supradestinatário superior (o terceiro), cuja compreensão responsiva absolutamente justa ele pressupõe quer na distância metafísica, quer no distante tempo histórico." (p. 333). Essa figura (ou instância), para Bakhtin, tem diferentes expressões ideológicas, dependendo da época e das concepções de mundo: Deus, a verdade absoluta, o povo, a ciência. Funciona, acima dos participantes concretos, como garantia a quem enuncia. Para Bakhtin, trata-se de "elemento constitutivo do enunciado total", como decorrência da natureza da palavra, que quer ser ouvida e, por isso, não fica restrita a uma compreensão imediata por outrem: humanamente "não existe nada mais terrível do que a irresponsividade" (p. $333){ }^{3}$

\footnotetext{
3 Ainda assim, em uma nota não imediatamente estendida, Bakhtin admite a ocorrência de uma palavra "que teme o terceiro e procura apenas o reconhecimento temporário... nos destinatários imediatos" (2003, p. 334).
} 
O tema do terceiro retorna, na Estética, nos Apontamentos de 19701971 (p. 367 et seq.). Bakhtin diz que as palavras de um indivíduo se dividem em suas próprias palavras e nas do outro, lembrando, contudo, que as fronteiras podem ficar confusas. Porém, essa questão é afastada ao se passar aos diversos campos da criação dialógica: aí se reconhece o terceiro, identificado como uma "posição objetiva" (de um conhecimento científico). O terceiro, neste ponto, é uma instância na qual um indivíduo pode colocar-se no lugar de outro - portanto, evocando a ideia de um lugar vazio, ocupável por outro na medida em que se situe na mesma posição - visto que é dispensada "a personalidade integral e ímpar do homem, isto é, onde o homem, por assim dizer, se especializa" (p. 380), atuando como "engenheiro", como "físico", enfim, como "cientista". A restrição aqui é que, apesar dessa especialização, dessa abstração em relação ao eu e ao $t u$, o caráter substitutivo deve ter limite. $\mathrm{Na}$ "vida vivenciável”, contudo, só existem as instâncias $e u / t u /$ ele - o fenômeno interacional.

Temos, pois, duas concepções de períodos distintos para "terceiro" na obra de Bakhtin. Cabe observar que, quando ele especifica os "tipos" que encarnam o(s) destinatário(s) de um evento interacional (endereçado), é perceptível uma gradação que vai desde o face a face mais coloquial até uma posição em que o destinatário é "indefinido". O destinatário pode ser

um participante-interlocutor direto do diálogo cotidiano, pode ser uma coletividade diferenciada de especialistas de algum campo especial da comunicação cultural, pode ser um público mais ou menos diferenciado, um povo, os contemporâneos, os correligionários, os adversários e inimigos, o subordinado, o chefe, um inferior, um superior, uma pessoa íntima, um estranho, etc.; ele também pode ser um outro totalmente indefinido, não concretizado (em toda sorte de enunciados monológicos de tipo emocional)... Cada gênero do discurso em cada campo da comunicação discursiva tem a sua concepção típica de destinatário que o determina como gênero. (BAKHTIN, 2003, p. 301). 
No caso dos "enunciados monológicos" a que o autor se refere neste recorte, imagino algo como expressar para sua interioridade, para justificar-se, para abrir-se, para dizer algo - uma espécie de ruminar. Algo a que uma pessoa próxima o suficiente poderia retrucar com: "Com quem você está falando?”

Entre a indefinição e o destinatário em pessoa no ato de comunicação discursiva, deve haver um espaço para inserir o destinatário que é o terceiro personalisticamente esvaziado na situação em que o sujeito individual pode ser substituído na mesma posição, tal como se viu acima com a segunda concepção de "terceiro": o físico, o engenheiro, o advogado, o geógrafo... Nessa linha gradual de possibilidades, não custa admitir mais uma instância (desta vez transcendendo), que corresponde ao "terceiro" como "alguém" que escuta e que entende perfeitamente o enunciador. Essa figura representa o ouvinte idealizado, que se poderia dizer coincidente com o próprio proferidor (o duplo) - espelho dele e termo de garantia da viabilidade de compreensão de seu enunciado, uma espécie de alter ego. Tanto é que o enunciador pode irritar-se com seu destinatário mais próximo, se julgar incorreta uma interpretação considerando que seu dizer era "suficientemente claro".

Com referência a esse "terceiro" projetado pelo enunciador, diz Todorov (1981, p. 170, tradução minha), (re)analisando Bakhtin: “mesmo se não há leitor ideal, que totalizaria o sentido do texto, isso não impede o autor de sonhar com isso; ao contrário: para compreender a estratégia da escrita, é preciso identificar esse 'supradestinatário' que o autor imaginou".

$\mathrm{Na}$ Análise de Discurso iniciada por Pêcheux, isso poderia ser associado ao que ele chama de esquecimento número dois: o sujeito tem a ilusão de selecionar, rejeitar, organizar aquilo que pode dizer ou não; imagina, também, que o que está dizendo é a expressão transparente da realidade. Ou seja: está remetendo seu dizer a um leitor-ideal (no sentido de Eco (1993)), tal como especifico na seção 4. Liga-se ao intradiscurso o fio do discurso.

Há matizes nesse tema que devem ser expostos, para evitar confusão conceptual. Dada a indefectível relação dialógica da 
comunicação discursiva, que obriga a uma amarra com a palavra alheia, também se dirá que essa palavra, tomada a montante no discurso (como fonte), é a primeira numa relação triangular; o locutor profere sua palavra - segunda - para um destinatário, o terceiro. Fique claro que isso é estabelecido explicitamente quando na teoria são exploradas as formas do discurso reproduzido (citado). O princípio, contudo, é geral: sempre há apropriação da palavra alheia (cf. PONZIO, 2008, p. 103).

Vejamos outra faceta da noção de "terceiro". Voloshinov (1981a [1926]), referindo-se ao papel de avaliação social da entonação, diz que "toda entonação é orientada segundo duas direções: voltada para o ouvinte como aliado e testemunha, e voltada para o objeto do enunciado como terceiro participante vivo; a entonação vitupera, acaricia, rebaixa ou alça às nuvens este último" (p. 197-198, grifo do autor). Quem é este terceiro? Ainda que restando indefinido, é a esse "referente" que se chama "tópico" - ou "herói" quando se trata de obra literária.

Há mais. Em A estrutura do enunciado, Voloshinov (1981b [1930]), ao defender o caráter dialógico do discurso interior, exemplifica com uma reflexão pessoal solitária, em que o indivíduo discute consigo mesmo: "Nossa consciência parece, assim, nos falar por duas vozes independentes, uma da outra, e cujos propósitos são contrários" (p. 294). E sucede aí que "uma dessas vozes se confunde com o que exprime o ponto de vista da classe à qual pertencemos, suas opiniōes, suas avaliações" (p. 295, grifos do autor). Trata-se de algo como uma "voz da consciência". Clot (2005) utiliza o termo 'subdestinatário' para essas vozes do diálogo interior. É o que ele chama "o pequeno diálogo" consigo mesmo, ao lado do "grande diálogo" com o terceiro participante invisível - o supradestinatário. Ou seja: “... endereçada(s) ao(s) destinatário(s) imediato(s), as réplicas são simultaneamente questões e respostas ao supradestinatário e ao subdestinatário" (2005, p. 40, tradução minha).

Vê-se, então, que há sentidos/acepções diferentes para o significante "terceiro", mas essa fluidez é também um convite à exploração de uma ou de todas elas, em sua dispersão.

Sophie Moirand (1988, p. 458, apud CHARAUDEAU; MAINGUENEAU, 2002, p. 560) revisitou a noção de "supradestinatário" no contexto dos discursos científicos, vendo essa instância como uma espécie de arquétipo da consciência coletiva correspondente ao domínio de referência do autor ou ao qual ele 
pretende aceder; haveria na "escuta", como "terceiro", além dos destinatários imediatos, algo como um representante mais típico do grupo referido. Penso que ela aproxima, nesse caso, a acepção primeira de Bakhtin que se viu aqui (instância transcendente dos saberes) e a segunda (a posição impessoal, despersonalizada, substituível). ${ }^{4}$ Aparentemente, essa instância também tem alguns traços do que Maingueneau denominou incorporação (v. as próximas seções).

\section{MAINGUENEAU: CENA DE ENUNCIAÇÃO, INCORPORAÇÃO E HIPERENUNCIADOR}

Arquivo, na teoria discursiva de Maingueneau (1991), reúne enunciados que se inscrevem num mesmo posicionamento, e são inseparáveis de uma memória e de instituições, as quais conferem sua autoridade e igualmente se legitimam por meio desses enunciados. Posicionamento remete a uma identidade enunciativa, um lugar de produção discursiva específico, designando tanto as operações que marcam essa identidade enunciativa como a própria identidade - o que não quer dizer que essa identidade seja fixa.

Com essa concepção, explica Maingueneau (2007, \8), é possível deslocar o olhar do texto para aquilo que o texto implica, visto que sua textualidade é necessariamente institucional. O gênero tem aí um papelchave: os analistas "não apreendem os lugares independentemente das palavras [paroles] que eles autorizam (contra a redução sociológica), nem as palavras independentemente dos lugares de que são parte pregnante (contra a redução linguística)". É significativo, da mesma forma, que o que ele nomeia como cena de enunciação não se reduz nem ao texto nem a uma situação de comunicação passível de descrever apenas do exterior.

Uma forma alternativa de expressar isso é, em Maingueneau (2008, p. 31), a característica que funda uma análise do discurso: "a opacidade do discurso, que não é redutível nem à língua, nem a instâncias sociais ou psicológicas". As práticas discursivas é que amarram as

\footnotetext{
${ }^{4}$ Aparentemente essa instância tem também alguma semelhança com a forma-sujeito (v. PÊCHEUX, 1988, p. 159 et seq.), tomada como representante do saber de uma formação discursiva, "sujeito universal", sujeito histórico - forma que seria responsável pela ilusão de unidade do sujeito por ela determinado e pela ilusão subjetiva de transparência do que é proferido.
} 
enunciações aos espaços instituídos, onde se criam as "instituições discursivas", que enlaçam uso da língua e lugar nos dispositivos que são os gêneros de discurso (MAINGUENEAU, 2008, p. 34).

A cena de enunciação (CE), no contexto do arquivo (MAINGUENEAU, 2001, p. 85 et seq.; 2004), presume espaço instituído, práticas discursivas (mediadas por gêneros) em sua construção (encenação). Não se trata de simples cenário: a $\mathrm{CE}$ se desdobra em três cenas distintas; essas subcenas funcionam como filtros relativamente a seus coenunciadores. A cena englobante fornece um status pragmático ao "tipo de discurso" implicado pelo texto (campo religioso, político, jornalístico, etc.); a cena genérica define-se por meio de gêneros particulares, com suas cenas específicas; a cenografia é o modo de aparecimento do gênero, seu ritual, seus recursos cenográficos. A publicidade, por exemplo, joga com múltiplas cenografias, para captar o público-alvo: conversação, discurso ambiental, humor, entretenimento. Quanto mais um gênero estiver voltado para a sedução do destinatário, tanto mais variada será a cenografia. ${ }^{5}$ Ao lado do enunciador e do coenunciador (destinatário), a cenografia tem ainda uma cronografia e uma topografia de onde surge o discurso - noções que não desenvolverei aqui.

$\mathrm{Na}$ seção 2, fiz referência ao "terceiro" de Bakhtin como um ouvinte idealizado que poderia coincidir (pelo menos parcialmente) com o próprio enunciador, como um duplo, um alter ego. Vou sintetizar agora o processo de incorporação em Maingueneau, para ver a possibilidade de pontos de contato ou correlação, considerando o enunciador e o destinatário nesse processo, relativamente ao papel do "terceiro" tal como perspectivado acima.

No processo enunciativo, a incorporação funciona, para Maingueneau (v. 2001; 2005b, p. 73), em três dimensões, que são funções do ethos, noção que diz respeito ao modo de aparecimento do enunciador, que mostra, por suas palavras, aspectos de seu caráter, de sua personalidade (sem falar disso explicitamente, e sem que a sinceridade seja condição):

\footnotetext{
${ }^{5}$ Esse jogo cenográfico parece corresponder àquilo que em Bakhtin são os gêneros intercalados: uma receita culinária em forma de poema; uma peça de humor apresentada em forma de linguagem científica, etc..
}

FURLANETTO - Hiperenunciador: o outro do supradestinatário? 
a) A leitura pelo destinatário vai permitir ao discurso proferido dar corpo ao enunciador, que aparece como fiador [garant] de uma fonte legitimadora (construída pelo destinatário);

b) O destinatário incorpora os esquemas desse fiador, sua maneira de ser, de se mover no mundo;

c) Esse duplo processo permite a incorporação imaginária do destinatário à comunidade daqueles que aderem a esse discurso. O destinatário não é passivo. ${ }^{6}$

Esse quadro mostra alguma familiaridade com a perspectiva de Moirand (1988) apresentada na seção 2: o destinatário leitor se incorpora imaginariamente à comunidade do enunciador.

Passo agora a examinar o que Maingueneau denomina hiperenunciador, para perspectivar posteriormente essa noção no contexto delineado.

Ultrapassando os locutores empíricos e os locutores coletivos partido, associação, etc. - chega-se ao nível de hiperenunciação, que se pode imaginar, em princípio, como tendo por espaço próprio o interdiscurso, tal como concebido em Análise do Discurso. É aí que se fundam pontos de vista sem que haja a possibilidade de uma identificação precisa - é o lugar das entidades transcendentes (não necessariamente transcendentais) que, de um modo ou outro, validam as enunciações proferidas.

O hiperenunciador surge na teoria de Maingueneau (cf. 2008) no contexto de outra noção: a particitação. O termo amalgama "participação" e "citação"; é uma palavra-valise, designando uma categoria que atravessa vários gêneros. Maingueneau vê aí uma forma específica de mobilizar o aparelho enunciativo. Diferente da "citação prototípica", a particitação tem estas características:

a) O enunciado citado é autônomo - originalmente ou tornado autônomo por extração de um texto;

\footnotetext{
${ }^{6}$ Observe-se este destaque de Maingueneau (2005b, p. 73): "Considerar o ethos dessa forma não implica que se conceba o escrito como o traço de uma oralidade primeira. [...] o tom específico que torna possível a vocalidade constitui para nós uma dimensão que faz parte da identidade de um posicionamento discursivo."
} 
b) Tal citação deve ser reconhecida por outrem sem que haja identificação de fonte (eventualmente marcada por algum deslocamento interno à enunciação: de caráter gráfico, fonético...);

c) Quem cita adere ao enunciado citado, que pertence ao que se chama thesaurus (um corpo de enunciados compartilhados por uma comunidade discursiva);

d) Por último, esse "tesouro" de enunciados será "ouvido" pela "voz" de um hiperenunciador, "cuja autoridade garante menos a verdade do enunciado... e mais amplamente sua 'validade', sua adequação aos valores, aos fundamentos de uma coletividade.” (MAINGUENEAU, 2008, p. 95).

Tendo em vista a novidade desse estudo e a variedade de situações sócio-históricas a considerar, Maingueneau limita-se a distinguir algumas "famílias" de particitação. Segue uma síntese, para que se compreenda como funciona a instância chamada hiperenunciador, que será aposta à de supradestinatário, como foco de minha discussão.

a) particitações sentenciosas - incluem a enunciação proverbial, em que o hiperenunciador aparece como "a sabedoria das nações" ou "a sabedoria popular" ("a vOz do povo é a vOz de Deus”) e o adágio jurídico (“contra fatos não há argumento”);

b) particitações gráficas - incluem as citações conhecidas, enunciados curtos e facilmente memorizáveis, organizados pela prosódia, pela rima, por figuras ("nenhum homem é uma ilha", "o mundo é uma aldeia”); a particitação bumanista ("errare humanum est; sed in errore perseverare dementis est", "homo sum, nihil humani a me alienum puto"7); e o thesaurus bíblico

\footnotetext{
7 "Errar é humano, mas persistir no erro é sinal de alienação" (Sêneca); "Sou homem; nada de humano, creio, deve ser estranho a mim" (Terêncio). As duas citações latinas foram buscadas por mim em Busarello (1998). Diz Maingueneau (2008, p. 100) que "os múltiplos autores do corpus humanista greco-latino valem menos como escritores individualizados do que como as múltiplas manifestações de um mesmo hiperenunciador, a 'Antiguidade', da qual todos participam." Nesse ponto o autor observa que o escritor que evoca esse hiperenunciador constrói o lugar de um leitor modelo que compartilha o seu thesaurus humanista.
} 
(“dai a César o que é de César, e a Deus o que é de Deus", "não é bom que o homem esteja só") ${ }^{8}$;

c) particitações de grupo - incluem particitações militantes, em que o enunciador é coletivo (partido, associação) e o hiperenunciador é transcendente: é a Esquerda, a Nação, quem sabe os Direitos Humanos, etc. Sua "voz" aparece como slogans (“o povo unido jamais será vencido"), como palavras de ordem, como os gritos de torcida (repetição ritual); particitações de comunhão, que pressupõem a fusão do grupo: orações (Pai Nosso, Ave Maria) e particitações com intérprete, campo dividido em dois grupos: narrativo (conto popular, mito) e poético (canção, poesia). Deve haver uma "instância mediadora" (representante) que atue adequadamente diante de um público (alocutário) que se identifica com certo repertório (thesaurus). É a Tradição, o Povo, um patrimônio que se manifesta como hiperenunciador, para além de quem narra (o particitador é um porta-voz). As marcas linguísticas mais visíveis, aqui, aparecem já no início: "Era uma vez...”, "Em tempos muito distantes..."

Ao final dessa categorização, Maingueneau (2008) traça uma linha para demarcar dois grandes tipos de hiperenunciador, com base no critério de atribuição de ponto de vista específico:

a) hiperenunciador passível de individuação: Deus;

b) sujeito universal dóxico, presente nos provérbios, adágios e outras fórmulas, empregadas sem marca de autoria. O hiperenunciador funciona como "uma instância responsável por uma memória", não como uma "consciência". Tem-se, então, um ethos fluido, não conteúdos proposicionais verificáveis.

\footnotetext{
${ }^{8}$ Maingueneau (2008, p. 102) destaca que, no thesaurus cristão, "o hiperenunciador é ao mesmo tempo locutor (a Bíblia é inspirada por Deus, mas Deus é também um dos locutores)", já no thesaurus humanista o hiperenunciador é a "Antiguidade".
} 


\section{TENTANDO ORDENAR OS FIOS TEÓRICOS}

Apresentei, na seção 3, o processo de incorporação perspectivado por Maingueneau. No terceiro passo, é dito que o destinatário incorporase à comunidade dos que aderem a um discurso: sente-se imaginariamente um membro dela ou tem o desejo de participar dela. No caso do discurso científico, tal como avaliado por Moirand (1988), como observei (na seção 2), o destinatário leitor, como membro de comunidade científica ou visando à participação nela, precisa sintonizar com um "terceiro", uma instância impessoal normativa. Há um deslocamento sensível em relação ao supradestinatário concebido primeiramente por Bakhtin (aquele que idealmente se oferece como escuta, legitimando a enunciação proferida). Agora esse "terceiro" é uma espécie de ordenador do que pretende entrar naquele discurso, e não com "quem" se conta para a compreensão/aceitação e proteção de um proferimento. $\mathrm{O}$ corpo que se forma pela leitura, na incorporação, não é um corpo simples, mas corpo da comunidade imaginária dos que aderem a um tipo de discurso (correspondente à cena englobante na terminologia de Maingueneau).

Essa questão é discutida por Maingueneau (2002) em Discours de savoirs, communautés de savants e em Détachement et surdestinataire. La correspondance entre Pascal et les Roannez. (2005a).

No primeiro trabalho, ele retoma a concepção de supradestinatário de Bakhtin no sentido de instância cuja compreensão responsiva é absolutamente exata (a primeira apresentada na seção 2) (2002, p. 6). Em seguida, ele remete ao trabalho de Moirand (1988) sobre o discurso científico, observando a ressignificação que ela faz do "terceiro" como um arquétipo do especialista de determinada disciplina. Como se trata, nesse artigo, da relação do pesquisador com revistas científicas notórias e de caráter transnacional ("partilhadas"), há um controle coletivo muito forte: 
Para escrever seus artigos, eles [os autores] devem construir-se a figura de um leitor modelo que chamaremos 'mundial', figura que é igualmente interiorizada pelo "editor" e os membros do "advisory board", cuja função é avaliar os textos a publicar. Cada membro do comitê de leitura interioriza a imagem desse leitor modelo pouco especificado que lhe serve de ponto de referência para suas críticas... eles devem legitimar esse lugar identificandose a um supradestinatário particularmente exigente $(2002$, p. 6 , tradução minha).

O supradestinatário, nessa acepção, é um terceiro crítico, avaliador, "leitor modelo" - como ressignificado por Moirand - cabendo ao autor conformar-se a suas exigências se desejar publicar.

Com outro desdobramento, o tema reaparece em Maingueneau (2005a) em seu estudo da correspondência de Pascal para os (irmãos) Roannez, que traz um dilema relativo aos destinatários das cartas, as quais têm um ethos impessoal. Maingueneau tenta verificar o que a cenografia instaura, e decide que as cartas se dirigem a um "supradestinatário" em conformidade com a doutrina jansenista. Nesse ponto, Maingueneau retorna à concepção de Bakhtin de um supradestinatário como no caso anterior, e da mesma forma retoma a ressignificação feita por Moirand (2008). A novidade aqui é esta: "Essas duas concepções do supradestinatário são perfeitamente compatíveis, como se vê aqui: Pascal enuncia simultaneamente para um supradestinatário exemplar, o cristão jansenista ideal, e para o supradestinatário divino.” (2005a, p. 8-9, tradução minha). ${ }^{9}$

Dada essa "duplicidade" de funções, Maingueneau adota a seguinte distinção: supradestinatário como representante típico do grupo (aqui, o jansenista) e supradestinatário que seria o fiador e o fundador (Deus) - por sua vez, também hiperenunciador do thesaurus dos textos cristãos citados nas cartas. Talvez essa coincidência seja bastante restrita, mas é um caso interessante, aberto ao estudo.

De minha parte, prefiro tomar o supradestinatário bakhtiniano como uma instância protetora e estimulante, legitimadora, o outro do

\footnotetext{
${ }^{9}$ Resta que o jansenista ideal não me parece ser, neste caso, um elemento cerceador, normatizador. Um leitor-modelo, sim (no sentido de Eco (1993)); v. adiante.
} 
enunciador que busca legitimação, em eventual confronto com a instância impessoal normatizada da qual ele procura se aproximar, no caso de legitimação de identidade com uma comunidade de discurso e sua "instituição discursiva" - que seria o "terceiro", num campo específico. Eu diria que, no contexto da obra de Bakhtin, destinatário aparece como termo genérico, e supradestinatário e terceiro como instâncias diferenciadas - cabendo ainda, no entanto, especificar os matizes da variedade apontada para "terceiro" (pelo menos dentro do próprio Círculo de Bakhtin).

Cabe ainda notar que, nos Apontamentos de 1970-1971, ao falar de "terceiro" como uma "posição objetiva" (BAKHTIN, 2003, p. 367 et seq.), instância na qual conta apenas uma especialidade (físico, fisiologista, analista), não se trata mais de um destinatário, mas de um enunciador numa posição mais ou menos impessoal - o que significa, nessa instância, que ele também será tratado como tal. É certo que, por ser impessoal, esse enunciador reflete um condicionamento ao campo disciplinar em que outro "terceiro" (instância de normatização) exerce seu poder de restrição, sem o qual não há legitimidade.

Observa-se, no desdobramento feito para situar e entender o funcionamento do "supradestinatário" e sua aparente correlação ao hiperenunciador - por identidade de nível (supra/hiper) - o surgimento de destinatários multifacetados, que será preciso categorizar, manifestando suas diferenças e nível de relevância teórica. Neste trabalho, apresentarei apenas um esboço do que pode ser desenvolvido. Há, contudo, ainda um elemento a considerar do lado da discussão sobre o supradestinatário: a ocorrência da expressão 'leitor modelo' em textos de Maingueneau (cf. 2002, p. 6; 2008, p. 100) - passagens citadas neste trabalho - o que me leva a investir, ainda que minimamente, na semiótica de Umberto Eco, que aborda essa instância paralelamente a 'autor-modelo'. Utilizarei aqui apenas o trabalho Superinterpretando textos, da obra Interpretação e superinterpretação (ECO, 1993), para verificar qual o papel/função do "leitor modelo", em Maingueneau, relativamente à instância trabalhada por Eco em sua semiótica da recepção. Presumo que caberá diferenciar leitor-modelo e destinatário (coenunciador).

O leitor-modelo (com hífen) de Eco surge em Lector in fabula, de 1979, e reaparece nas obras subsequentes. Vejamos: "Um texto é um dispositivo concebido para produzir seu leitor-modelo... Um texto pode 
prever um leitor-modelo com o direito de fazer infinitas conjeturas" (1993, p. 75). O leitor empírico (contraparte do leitor-modelo) é, então, um agente que faz conjeturas sobre o tipo de leitor-modelo que o texto postula. Esse parece o caso tal como explorado por Maingueneau (2002) em Discours de savoir, communautés de savants, dada a previsão das exigências: "Para escrever seus artigos, eles [os autores] devem construir-se a figura de um leitor modelo" (p. 6); na outra passagem, quando Maingueneau se refere à particitação humanista, encontra-se: "O escritor constrói o lugar de um leitor modelo... com o qual ele comunga por sua própria particitação" (2008, p. 100). Aparentemente, há um deslizamento em relação à primeira ocorrência, visto que a carga de exigência para um autor está aqui no mínimo dissimulada. Ademais, não se supõe que o leitor seja um pretendente àquela comunidade. Isso se parece mais, então, com o leitor-modelo de Eco, voltado à questão da interpretação. ${ }^{10}$

O texto, diz Eco, "mais do que um parâmetro a ser utilizado com a finalidade de validar a interpretação, [...] é um objeto que a interpretação constrói no decorrer do esforço circular de validar-se com base no que acaba sendo o seu resultado" (1993, p. 75). Esta outra explicação de Eco mostra algo que é pacífico no corpo da análise de discurso (a marginalidade do autor empírico):

Minha ideia de interpretação textual como a descoberta da estratégia com intenção de produzir um leitor-modelo, concebido como a contrapartida ideal de um autor-modelo (que aparece apenas como uma estratégia textual), torna a ideia da intenção do autor empírico radicalmente inútil. Temos de respeitar o texto, não o autor enquanto pessoa assim-e-assim. (1993, p. 76).

Esse leitor-modelo permitiria uma leitura econômica do texto, seguindo certas diretrizes. No entanto, Eco observa que na comunicação cotidiana há casos em que a inferência sobre a intenção de quem fala é importante, e possivelmente teria importância quando se trata de textos escritos com autor empírico vivo, que pode reagir às interpretações feitas. Faço essa observação porque ela tem a ver com o supradestinatário bakhtiniano em sua primeira função: ser o leitor ideal,

10 Talvez seja uma tática de Maingueneau não usar hífen em "leitor modelo", não se comprometendo com a noção desenvolvida por Eco. É apenas conjetura minha. 
o entendedor. De fato, um autor empírico se dá o direito de reagir a interpretações que julgar incorretas ou mesmo desastradas.

O leitor-modelo de Eco representaria uma instância com alguma aproximação do supradestinatário de Bakhtin (em sua acepção mais típica, como estou tratando): ele se conformaria a um desejo de autor, que o construiu para uma interpretação condizente com seu projeto, e que justifica, por isso, esse projeto.

Antes de passar a minhas reflexões conclusivas, apresentarei sinteticamente uma proposta inicial para visualizar as várias instâncias observadas neste levantamento, mostrando a heterogeneidade de vozes participantes.

Comecemos pelo destinatário imediato - pragmaticamente falando, como participante-interlocutor. Ele pode ser: um interlocutor direto; uma coletividade; os pares (correligionários); os adversários, inimigos; um superior; um subordinado; uma pessoa íntima; um outro indefinido, etc. "Cada gênero do discurso em cada campo da comunicação discursiva tem a sua concepção típica de destinatário que o determina como gênero", diz Bakhtin (2003, p. 301). Essa é uma base para os desdobramentos que observamos.

Quanto ao supradestinatário, será a instância que compreende perfeitamente o enunciador (e nisso se aproxima do leitor-modelo de Eco), separando-o da função de "terceiro", que aparece multiplamente como:

a) enunciador impessoal (posição objetiva, em espaços que assim o exijam);

b) arquétipo de uma comunidade a que o enunciador pertence ou a que aspira ("leitor modelo", relacionado à "incorporação" no sentido de Maingueneau);

c) duplo (alter ego, mas não equivalendo ao nível do supradestinatário); 11

d) forma-sujeito idealizada de uma formação discursiva (Pêcheux);

\footnotetext{
${ }^{11}$ Essa categoria me parece ainda um pouco fluida, mas vou mantê-la neste momento.
} 
e) objeto do enunciado (ele/tópico) (Voloshinov);

f) voz da consciência (ponto de vista de um grupo/comunidade, aparente na conversação interna do enunciador, em conflito com outra voz interior (Voloshinov);

g) subdestinatário no "pequeno diálogo" (Clot).

Quanto ao hiperenunciador, ele se oferece como um enunciador idealizado, responsável por uma memória; é instância produzida pelo enunciador, que o "ocupa" em função de seu contexto sociocultural. Tem duas modalidades de ocorrência:

a) individuado (Deus, Jesus Cristo, santos, padres da Igreja...);

b) sujeito universal dóxico (voz do povo, nação, tradição...)

Em que medida essas vozes se tocam, distanciam-se, marcam uma história e uma memória, traçando um trajeto na rede? Inevitavelmente, fazem lembrar que o discurso é produto do interdiscurso. Como expressou Authier-Revuz (1984, p. 100, tradução minha), "nenhuma palavra é neutra, mas sempre 'carregada', 'ocupada', 'habitada', 'atravessada' pelos discursos nos quais 'viveu sua existência socialmente subentendida"'. Authier-Revuz também utiliza a concepção de "sujeito dividido" (clivado, termo da psicanálise), considerando que na cadeia linear do intradiscurso se pode ouvir a polifonia não intencional do discurso, sintoma do atravessamento pelo inconsciente (Outro). É especialmente na "conotação autonímica"12 que se marca essa alteridade em suas múltiplas ocorrências, sem identificação imediata (embora também possa ser glosada).

Essa rede intricada das instâncias discursivas, atentando-se agora para o foco da discussão, tem no hiperenunciador uma instância correspondente ao supradestinatário, sinalizada por um vetor, que é o endereçamento: um enunciador, em circunstâncias específicas num campo histórico-social e cultural, tem à disposição uma memória na qual a figura do hiperenunciador representa amplas possibilidades. Seu projeto, endereçado a um destinatário (com sua identificação -

\footnotetext{
${ }^{12} \mathrm{Um}$ fragmento mencionado é ao mesmo tempo usado, de modo que ele se integra ao fio do discurso, sem deixar marca sintática saliente. É uma espécie de "contaminação" do discurso por algo que vem do exterior (alteridade compondo a unidade).
} 
ouvinte/leitor-modelo? - no campo em questão, mas não necessariamente $\left.{ }^{13}\right)$, chega a esse destinatário, mas não se detém nele: busca um supradestinatário (a instância protetora). No início e no final desse percurso notamos que uma e outra instâncias têm, aparentemente, as mesmas "expressões ideológicas", ou semelhantes: Deus, a Nação, a Tradição, o Império, o Reino, a Antiguidade, a voz da Razão, a Ancestralidade... O hiperenunciador se oferece como instância mergulhada no interdiscurso, e o supradestinatário - como no caso analisado por Maingueneau, em que, nas cartas de Pascal, Deus apareceria simultaneamente como hiperenunciador e supradestinatário (cf. início desta seção) - poderia, reversamente, coincidir com o primeiro. Figurativamente, é como se fizéssemos o retângulo da figura 1 formar um cilindro, fazendo tocar as laterais, permitindo que supradestinatário e hiperenunciador se aproximassem.

Apesar dos riscos da simplificação de um esquema, segue uma tentativa de visualizar minha interpretação:

\section{Figura 1 - Esquema de uma possível correlação hiperenunciador/supradestinatário:}

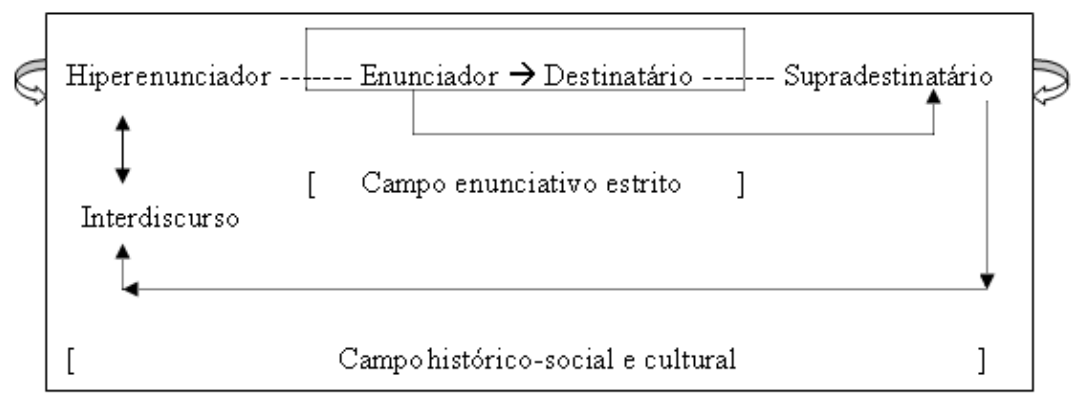

Fonte: Elaboração própria.

\footnotetext{
${ }^{13} \mathrm{O}$ hiperenunciador presume um espaço específico onde ele pode assomar, mas isso não significa que o destinatário se obrigue a conhecer profundamente esse campo. Ele não será, certamente, o leitor-modelo.
} 
Resta tocar num ponto, apenas para situar algumas consequências imediatas do entendimento apresentado acima.

Uma aproximação à noção de autoria, considerando os aspectos discutidos aqui, seria a implicação observada nesse trajeto tortuoso que aproxima e distancia os coenunciadores: um autor (em qualquer nível), em sua complexidade, formula para uns, pensando em si mesmo e indo além, transcendendo em sua angústia pessoal de ser entendido - ora manifestando-se mais intimamente ("eu sinto"), ora cuidando mais de seu interlocutor (tu), ora expondo mais ou resguardando seu "referente" (ele), ora exorbitando em sua necessidade de compreensão, reconhecimento e respondibilidade (o supradestinatário idealizado). São direções que precisam equilibrar-se para a obtenção dos efeitos desejados.

Dada a heterogeneidade constitutiva do discurso, sujeito e discurso estão ameaçados continuamente de se desfazerem. É assim que, conforme Authier-Revuz (1984, p. 107, tradução minha), "para o sujeito dividido, o papel, indispensável, do Moi [ego] é o de uma instância que, no imaginário, se ocupa em reconstruir a imagem de um sujeito autônomo, anulando, no desconhecimento [méconnaissance], o descentramento real". É desse confronto que nasce a percepção de autoria: cria-se uma identidade, um corpo discursivo e uma figura de sujeito enunciador, dominando o exterior que "acontece" nele.

\section{NOTAS A TÍTULO DE CONCLUSÃO}

O que se percebe, com essa reflexão, é que a concepção de supradestinatário derivou uma dispersão de sentidos e usos. Ela está sendo observada por vários ângulos, o que mostra, mais que tudo, uma fragmentação subjetiva que, em última análise, vai abrindo para uma compreensão mais apurada da multifacetação do discurso e do sujeito. $\mathrm{O}$ entendimento de supradestinatário vai desde uma instância vinculada ao ego, um duplo do enunciador, até uma instância externa, independente do enunciador (o terceiro com marca coletiva), como um conjunto de 
normas a que é preciso se apegar para a aceitação do texto (numa comunidade de discurso), estendendo-se ainda a uma forma de discurso interior, até, eventualmente, coincidir com o hiperenunciador (conforme Maingueneau).

Encontra-se essa imensa variedade porque a cultura sobrevive nos seus enunciadores e destinatários (coenunciadores). Ainda que com vazios e esquecimentos, eles são tributários dessa cultura. Esse outro é trans-histórico: uma história coletiva de civilização do real (CLOT, 2005, p. 39). Ou ainda, relembrando Bakhtin, pelas palavras de Clark e Holquist (1998, p. 39): “minhas palavras já vêm envoltas em muitas camadas contextuais sedimentadas pelas numerosas intralinguagens e pelos vários patoás sociais, cuja soma constitui 'a' linguagem de meu sistema cultural”.

\section{REFERÊNCIAS}

AUTHIER-REVUZ, J. Hétérogénéité(s) énonciative(s). Langages, n. 73, p. 98111, mars 1984.

BAKHTIN, M. Estética da criação verbal. Trad. de Paulo Bezerra. São Paulo: Martins Fontes, 2003.

BUSARELLO, R. Máximas latinas para o seu dia-a-dia. 2. ed. Florianópolis: Ed. do Autor, 1998.

CHARAUDEAU, P.; MAINGUENEAU, D. Dictionnaire d'Analyse du Discours. Paris : Seuil, 2002.

CLARK, K.; HOLQUIST, M. Mikhail Bakhtin. São Paulo: Perspectiva, [1984] 1998.

CLOT, Y. L'autoconfrontation croisé en analyse du travail. In: FILLIETTAZ, L.; BRONCKART, J.-P. (Éd.). L'analyse des actions e des discours en situation de travail: concepts, méthodes et applications. Louvain-la-Neuve: Peeters, 2005. p. 37-55.

ECO, U. Superinterpretando textos. In: Interpretação e superinterpretação. São Paulo: Martins Fontes, 1993. p. 53-77. 
MAINGUENEAU, D. L'Analyse du Discours: introduction aux lectures de l'archive. Paris : Hachette, 1991.

Análise de textos de comunicação. São Paulo: Cortez, 2001.

. Discours de savoir, communautés de savants. In: EHLICH, K. (Hg.).

Europäische Wissenschaft/Europäische Perspektiven. Münch, 2002.

Disponível em: <http:// www.euro-sprachenjahr.de/Maingueneau.pdf $>$. Acesso em: 27 jan. 2010.

- ¿"Situación de enunciación” o “situación de comunicación”? Revista electrónica Discurso.org, n. 5, 2004. Disponível em:

$<$ http://www.revista.discurso.org/articulos/Num5

_Art_Maingueneau.htm>. Acesso em: 5 jun. 2009.

. Détachement et surdestinataire: la correspondance entre Pascal et les Roannez. Semen, n. 20, 2005a. Disponível em:

< http://semen.revues.org/document1086.html>. Acesso em: 27 jan. 2010.

. Ethos, cenografia, incorporação. In: AMOSSY, R. (Org.). Imagens de si no discurso: a construção do ethos. São Paulo: Contexto, 2005b. p. 69-92.

. L'idéologie : une notion bien embarrassante. COnTEXTES: Revue de sociologie de la littérature, $\mathbf{n}$. 2, février 2007. Disponível em:

<http://contextes.revues.org/index189.html>. Acesso em: 13 jun. 2009.

. Cenas da enunciação. São Paulo: Parábola, 2008.

MOIRAND, S. Une histoire de discours. Paris: Hachette, 1988.

PÊCHEUX, M. Semântica e discurso: uma crítica à afirmação do óbvio. Campinas: Ed. da Unicamp, 1988.

PONZIO, A. A revolução bakhtiniana. São Paulo: Contexto, 2008.

TODOROV, T. Mikhail Bakhtine: le principe dialogique. Suivi de Écrits du Cercle de Bakhtine. Paris: Editions du Seuil, 1981.

VOLOSHINOV, V. [1926] Le discours dans la vie et le discours dans la poésie. In: TODOROV, T. Mikhail Bakhtine: le principe dialogique. Suivi de Écrits du Cercle de Bakhtine. Paris: Editions du Seuil, 1981a. p. 181-215.

[1930]. La structure de l'énoncé. In: TODOROV, T. Mikhail

Bakhtine: le principe dialogique. Suivi de Écrits du Cercle de Bakhtine. Paris: Editions du Seuil, 1981b. p. 287-316. 
Recebido em 08/08/11. Aprovado em 21/04/12.

Title: Hyperenunciator: the other of superaddressee?

Author: Maria Marta Furlanetto

Abstract: This essay aims to verify if the notion of "byperenunciator", proposed and developed by Maingueneau $(2005 a, 2008)$ in his last works on discourse analysis, would have any correlation with the generic notion of "third" (investigated in its variants) in the theory of Bakbtin's Circle. The proposition bere is to examine an approximation or inspiration to review issues associated to established genres, including the authorship, seeking to establish their mode of operation and the implications as regards the process of authorship. It is noted, in conclusion, that the understanding of superaddressee (as a "third virtual person") goes from an instance bound to the ego, a double of the enunciator, up to an external body, regardless of the enunciator (the third with collective mark), as a set of rules that one must follow for the acceptance of the text (in a community of discourse), extending to a form of inner speech until it, eventually, coincides with the byperenunciator.

Keywords: Discourse. Hyperenunciator. Superaddressee. Authorship.

Titulo: Hiperenunciador: ¿el otro del supradestinatario?

Autor: Maria Marta Furlanetto

Resumen: El objetivo en este ensayo es verificar si la noción de "biperenunciador", propuesta y desarrollada por Maingueneau (2005a, 2008) en sus últimos trabajos de Análisis del Discurso, tendría correlación con la noción genérica de "tercero" (investigada en sus variantes) en la teoría del Círculo de Bakbtin. Se tiene como propuesta examinar una aproximación o inspiración para rever cuestiones asociadas a los géneros instituidos, incluyendo la autoría. Se busca establecer su modo de funcionamiento y las implicaciones relativas al proceso de autoría. Se observa, en conclusión, que el entendimiento de supradestinatario (como "tercero") va desde una instancia vinculada al ego, un doble del enunciador, hasta una instancia externa, independiente del enunciador (el tercero con marca colectiva), como un conjunto de normas que es preciso seguir para la aceptación del texto (en una comunidad de discurso), extendiéndose incluso a una forma de discurso interior, hasta, eventualmente, coincidir con el biperenunciador.

Palabras-clave: Discurso. Hiperenunciador. Supradestinatario. Autoría.

FURLANETTO - Hiperenunciador: o outro do supradestinatário? 